Resumen: Se analiza el derecho a la propia imagen destacando la protección de la imagen personal en la legislación. Se hace referencia a la normativa internacional y de algunos países, pero en particular de la República Argentina que acaba de incorporar reglas al respecto en la unificación de su Código Civil y Comercial. Asimismo, se incluyen ejemplos de resoluciones judiciales que deciden respecto al derecho de la imagen. Por último, se analiza la protección legal de la imagen profesional como construcción de reputación laboral.

Palabras claves: derecho a la imagen - protección legal - normas - imagen profesional -casos judiciales.

[Resúmenes en inglés y portugués en la página 122]

${ }^{(*)}$ Abogada y Contadora Pública por la Universidad de Buenos Aires, Master en Derecho Empresario por la Universidad Austral y Doctora en Derecho por la Universidad de Salamanca. Premio extraordinario de Doctorado 2011-2012.

\title{
Introducción
}

La imagen resulta la representación de nuestra identidad y nos permite diferenciarnos de otros. Ella exhibe los detalles de nuestro ser y de una personalidad diversa entre el resto de los seres humanos.

Siendo la imagen tan esencial para cada individuo, el Derecho, como ordenador de conductas sociales, no puede ignorar su importancia. Por eso, las distintas legislaciones del mundo han dictado, en mayor o menor medida, las reglas para resguardar la imagen humana. Así, la Constitución Española, por ejemplo, en su artículo 18.1. garantiza el derecho de la propia imagen (Rougés, 2009). Es decir, el derecho español eleva la protección de la imagen al nivel de las normas fundamentales de la sociedad hispana. En la República Argentina, sin embargo, sólo se encuentra contemplado el resguardo de la imagen en el Código Civil y Comercial de la Nación cuando reglamenta los compromisos internacionales que obligan al país a preservar la imagen como derecho básico de las personas. Así en sus artículos 52 y 53 del Capítulo referido a Derechos y actos personalísimos contempla la 
afectación a la dignidad realizada a través de una lesión a la imagen y prohíbe captar o reproducir la imagen sin consentimiento de la persona, salvo algunas excepciones (Villalba Díaz, 2015). El Código, además, iguala la imagen a la voz humana reconociéndola como signo distintivo.

El Diccionario del Español Jurídico ${ }^{1}$ indica que imagen, para el Derecho, es el conjunto de rasgos o detalles físicos que identifican a una persona. Detalla el uso del término tanto en el ámbito del derecho constitucional como del derecho penal. En el primero en orden a controlar la "captación, difusión y, en su caso, explotación de los rasgos físicos que hacen reconocible a una persona como sujeto individualizado". Este derecho constitucional da lugar a la protección de la vida privada de modo de permitir o prohibir la divulgación de la figura. Con relación al derecho penal se produce la tipificación de conductas lesivas de la imagen, directa o indirectamente, como las lesiones o las calumnias e injurias donde, en la primera, la pena máxima puede llegar a la privación de la libertad a causa del delito cometido.

Ambos derechos, el constitucional y el penal, se refieren a la tutela y reconocimiento que hace el Derecho Público Estatal de la imagen. Ellos determinan el interés de la sociedad en resguardar este derecho como valor comunitario. En cambio, el Derecho Privado se ocupa de las relaciones interpersonales que se producen con relación al derecho subjetivo irrenunciable de la propia imagen.

\section{El derecho a la propia imagen}

Cuando hablamos de los derechos de las personas nos referimos a la facultad que le otorga la legislación vigente en un momento determinado y en un lugar específico para que se les reconozca una prerrogativa particular. En este caso, la protección de la propia imagen. Existen, sin embargo, derechos que son reconocidos a los individuos a nivel internacional además de su admisión local. Es decir, se conceden derechos sobre la imagen a los sujetos en forma idéntica en distintos países del mundo.

Así, ya en el año 1948, la Asamblea de Naciones Unidas aprobó la Declaración Universal de los Derechos Humanos y allí, si bien no existe una referencia específica a la propia imagen, el artículo 12 establece que nadie podrá ser objeto de injerencias arbitrarias en su vida privada, ni podrá sufrir ataques a su honra o a su reputación. Por ello, los países miembros de Naciones Unidas en los diversos documentos y tratados internacionales incluyen el compromiso de protección de este derecho que, a mi criterio, es la garantía de resguardo a la propia imagen.

Se reitera este amparo en el Pacto Internacional de Derechos Civiles y Políticos del año 1966 con similares términos. Pero, en su artículo 19, también se hace referencia a la libertad de expresión con el debido respeto de los derechos y la reputación de los demás. Como la imagen es la expresión de la identidad destaco lo relevante que resulta que la comunidad internacional asegure a cada persona el derecho de mostrarse como desea.

Conforme lo expresado, se pueden considerar dos cuestiones referidas al derecho a la propia imagen y su relación con otros derechos. La primera se refiere a la dignidad y la honra. La segunda a la libertad de expresión. 
Respecto a la dignidad y la honra se debe apuntar que son dos derechos distintos del derecho a la propia imagen, pero íntimamente vinculados. El derecho a la propia imagen es autónomo de modo que no necesita estar relacionado con otro derecho para ser protegido (Rougés, 2009; Aliaga, 2012). Se ampara la imagen como tal si bien la mayoría de las veces la perturbación de la imagen se ve acompañada de una falta de respeto a la dignidad o de una afectación del honor. De modo tal que, la imagen debe cuidarse tanto en vida de la persona como luego de su fallecimiento, teniendo derecho los herederos de cuidar la imagen del difunto (Villalba Díaz, 2015).

La libertad de expresión, en orden a la manera en que el individuo quiere ser visto o recordado, tiene un límite ya que se encuentra prohibido violar los derechos de otros y perjudicar valores sociales esenciales como la paz.

\section{Protección de la imagen personal}

El derecho a la propia imagen es un derecho fundamental enmarcado en lo que se denominan derechos personalísimos, derechos de la personalidad o derechos existenciales (Navarro, 2016, p. 12). Es decir, son aquellos derechos inherentes a la persona humana y que le son reconocidos por el sólo hecho de su existencia (Villalba Díaz, 2003).

Si un individuo goza de un derecho de características particulares, tal como el derecho a la propia imagen, entonces, debe gozar de herramientas eficientes que garanticen el ejercicio del derecho otorgado frente a otros sujetos.

De este modo no sólo existe un mecanismo positivo de poder disponer de la imagen personal sino también la posibilidad de prohibir o autorizar a otros la utilización de esa representación de uno mismo que es la imagen y solicitar reparación por el daño infringido a la propia imagen (Villalba Díaz, 2015).

Existen situaciones que demuestran que no sólo la imagen fiel retratada en una fotografía, en una pintura o una caricatura puede identificar a determinada persona, sino que hay signos, vestimentas, colores o formas que pueden llevar al convencimiento de terceros que hay alguien en particular involucrado que se manifiesta a través de esos símbolos. Se suele hablar de "personalización de las cosas" (Villalba Díaz, 2015) como serían los anteojos de John Lennon, el bigote o el sombrero de Charles Chaplin o la sonrisa de Carlos Gardel. Estas caracterizaciones no se pueden asemejar en todas las situaciones a la imagen misma de la persona. En distintas causas judiciales se ha demostrado, a través de sentencias diversas, que no siempre se debe proteger la representación del mismo modo que se ampara la imagen (O.A.J.M. s/medidas cautelares, 2017).

En igual sentido no se resguarda de igual manera la imagen precisa y total del individuo que algunas partes del cuerpo. Esto es así porque las parcialidades muchas veces no evocan determinada identidad.

La utilización de la imagen tanto por su titular como de terceros puede tener tanto impacto personal como patrimonial (Rougés, 2009). En este último sentido tanto el dueño de la imagen puede utilizarla para la obtención de lucro como cederla para que sean terceros quienes se beneficien con su uso. Esta concesión de derecho de la imagen personal generalmente tiene un valor económico, un plazo, una localización determinada, uno o varios 
medios de difusión autorizados y una restricción respecto al tipo específico de uso que se permite ya sea publicitario, comercial o periodístico (N.M.A. c/ Palermo Films, 2017). La regla general es que nadie puede captar, difundir o publicar la imagen de otro sin su autorización (Villalba Díaz, 2003). Sin embargo, en algunas legislaciones se contempla la posibilidad del uso cuando el interés público así lo impone (G.B.D. c/ Yahoo!, 2017). El Derecho Civil se ocupa de regular estas relaciones contractuales que exceden el amparo constitucional que no refiere al orden económico que involucra la imagen.

\section{La imagen profesional}

En particular, quien ejerce una profesión, vinculada o no con la imagen, realiza una construcción especial que intenta comunicar el tipo de servicio o trabajo que realiza y la calidad de la prestación (Bello Knoll y Estebecorena, 2017). Dentro de ese armado se transmite también aquello que el profesional quiere destacar para diferenciarse de otros (Erner, 2013, p. 93).

Hablamos aquí de una representación pública que puede ser igual o diferente de la identidad privada de la persona pero que pretende un significado en el marco de la labor que desempeña.

La tarea referida a esa elaboración de imagen profesional también es protegida por el Derecho. En este caso por las normas de propiedad intelectual como, por ejemplo, el registro de la imagen como marca (Villalba Díaz, 2015).

La especialización en un área determinada permite una mayor diferenciación respecto a diversos colegas y facilita la comunicación. Pero toda exteriorización debe formar parte de una estrategia global que sea coherente con el objetivo del modelo que se pretende transmitir. La inconsistencia siempre es perjudicial para la imagen profesional (Bermúdez c/ Artear, 2017).

Los manuales de procedimiento y la descripción de métodos de trabajo suponen un desarrollo particular que también pueden ser resguardados por las normas de propiedad intelectual.

Aquí ya no sólo se habla del retrato como representación del profesional sino de toda la percepción que los terceros tienen respecto de su trabajo, es decir, su reputación (Díaz Soloaga, 2007, p. 193). Ya entonces el Derecho acude en auxilio de la defensa de ella con reglas de Derecho Público y, en particular, se despliegan normas para cada profesión. Tal es así que en el caso de los abogados en la República Argentina la ley que regula su ejercicio profesional impone el dictado de códigos de ética en cada jurisdicción que contemplan diversas situaciones que hacen al cuidado y protección de la imagen profesional. En este sentido las sanciones por el incumplimiento de las disposiciones establecidas pueden llevar a la prohibición del ejercicio de la profesión tanto temporaria como definitivamente. La globalización ha obligado a los profesionales a dedicar especial atención a la información que transmiten de sí mismos para evitar la uniformidad y la igualación con otros (Barnard, 2014, p. 177). 


\section{Conclusiones}

Para el Derecho se asimila la imagen con la identidad. Por ello, las normas base que regulan la vida en cada sociedad contemplan la protección de la representación del individuo. Ello es así porque la comunidad internacional coincide en la necesaria defensa de derechos esenciales y comunes a todo ser humano.

Los mecanismos legales fijados en las distintas jurisdicciones proponen amparar tanto el ámbito personal como el patrimonial de la imagen sea en su faz privada como pública. En algunos casos este cuidado se extiende a conceptos amplificados de la imagen como partes del cuerpo o personalizaciones de cosas.

La imagen profesional goza del auxilio del Derecho en cuestiones diversas que no sólo involucran el concepto de imagen como representación inevitable del individuo sino extendida a la construcción de su reputación laboral.

El Derecho regula las conductas humanas que involucran la imagen tanto personal como profesional, sean estas idénticas o diversas según la propia decisión del individuo que goza de la libertad de construir el modo en que desea mostrarse a los otros.

\section{Notas}

1. Recuperado de: http://dej.rae.es/\#/entry-id/E135510

\section{Referencias bibliográficas}

\section{Libros y artículos de revistas jurídicas.}

Aliaga, J. (2012). La autonomía del derecho de imagen. Comentario a fallo "Aleman, C. c/ Telepiu SA s/daños y perjuicios”. Buenos Aires, República Argentina. Revista jurídica digital. Editorial Eldial.com. Eldial DC1958.

Barnard, M. (2014). Fashion theory. An introduction. New York, United States. Routledge Editors.

Bello Knoll, S.I., y Estebecorena, M.P. (2017). Imagen y comunicación estratégica de los abogados. Buenos Aires, República Argentina. Revista jurídica digital. Editorial Eldial. com. Eldial DC2407.

Díaz Soloaga, P. (2007) ¿Cómo gestionar marcas de moda? Madrid, España. Cie Inversiones Editoriales.

Erner, G. (2013). Sociología de las tendencias. Barcelona, España. Editorial Gustavo Gili.

Navarro Floria, J.G. (2016). Los derechos personalísimos. Buenos Aires, República Argentina. Editorial El Derecho.

Rougés, C. (2009). La necesidad del consentimiento para la utilización comercial de la imagen de las personas: una sentencia del Tribunal Supremo de Madrid a contramano de ese derecho. Buenos Aires, República Argentina. Revista jurídica digital. Editorial Eldial. com. Eldial DC10E3. 
Villalba Díaz, F. A. (2003). Aspectos patrimoniales y extrapatrimoniales de la propia imagen. Buenos Aires, República Argentina. Revista jurídica digital. Editorial Eldial.com. Eldial DC24C.

Villalba Díaz, F. A. (2015). El derecho a la imagen en el Código Civil y Comercial de la Nación. Buenos Aires, República Argentina. Revista jurídica digital. Editorial Eldial.com. Eldial DCIF50.

\section{Fallos judiciales.}

Causa 31873/2012. N.,M.A.c/Palermo Films SA s/diferencias de salarios. CNTRAB-Sala IX17/11/2017. Editorial Eldial.com. elDial.com AAA440.

Causa 46390/2017. O.,A.,J., M. s/medidas cautelares. CNCIVY COMFED-Sala I-29/08/2017. Editorial Eldial.com. elDial.com AAA2CE.

Expte. 14884/2007. Bermudez, G.A. c/ Artear SA s/ordinario. CNCOM-Sala B-25/10/2017. Editorial Eldial.com. elDial.com AAA37B.

Expte. 33240/2013. G.,B.D. c/ Yahoo Argentina S.R.L. s/daños y perjuicios. CNCIV-Sala B-29/11/2017. Editorial Eldial.com. elDial.com AAA401.

\section{Páginas web.}

Real Academia Española RAE (2016). Diccionario del Español Jurídico. Madrid, España. Recuperado de: http://dej.rae.es/\#/entry-id/E135510

\section{Fallos judiciales}

Causa 31873/2012. N.,M.A.c/Palermo Films SA s/diferencias de salarios. CNTRAB-Sala IX17/11/2017. elDial.com AAA440.

Causa 46390/2017. O.,A.,J., M. s/medidas cautelares. CNCIVY COMFED-Sala I-29/08/2017. elDial.com AAA2CE.

Expte. 14884/2007. Bermudez, G.A. c/ Artear SA s/ordinario. CNCOM-Sala B-25/10/2017. elDial.com AAA37B.

Expte. 33240/2013. G.,B.D. c/ Yahoo Argentina S.R.L. s/daños y perjuicios. CNCIV-Sala B-29/11/2017. elDial.com AAA401.

\section{Páginas web}

Real Academia Española (2016). Diccionario del Español Jurídico. Madrid, España. Recuperado de: http://dej.rae.es/\#/entry-id/E135510

\footnotetext{
Abstract: The right to one's own image is analyzed, highlighting the protection of the personal image in the legislation. Reference is made to international regulations and to certain countries, but in particular to the Argentine Republic that has just incorporated rules in this regard in the unification of its Civil and Commercial Code. Also, examples of judicial decisions that decide on the right of the image are included. Finally, the legal protection of the professional image as a construction of a professional reputation is analyzed.
} 
Keywords: right to the image - legal protection - norms - professional image - judicial cases.

Resumo: $\mathrm{O}$ direito à própria imagem é analisado, destacando a proteção da imagem pessoal na legislação. Faz-se referência aos regulamentos internacionais e a certos países, mas em particular à República Argentina que acaba de incorporar regras nesse sentido na unificação de seu Código Civil e Comercial. Além disso, exemplos de decisões judiciais que decidem sobre o direito da imagem estão incluídos. Finalmente, a proteção legal da imagem profissional como construção de uma reputação profissional é analisada.

Palavras chave: direito à imagem - proteção legal - normas - casos profissionais de imagem judicial.

[Las traducciones de los abstracts fueron supervisadas por el autor de cada artículo] 